\title{
Risk Management and Judicialization
}

\author{
Caroline Lacroix
}

\begin{abstract}
Industrial or public transport accidents are referred to the court of justice and often result in high-profile trials. This criminalization process raises the question of the place of repressive justice and the issue of the debate around the judicialization of such serious events. Beyond that, how is this penalization translated? Since the actual conditions for the safety of at-risk activities rely on a set of factors (compliance with norms, rules and procedures, experience of safety culture actors, etc.), how does the judge assess fault and what place is allocated to expertise?
\end{abstract}

Keywords Judicialization $\cdot$ Disaster $\cdot$ Risks $\cdot$ Criminal trial $\cdot$ Involuntary manslaughter $\cdot$ Responsibilities $\cdot$ Judge $\cdot$ Expertise

\section{Introduction}

Public transport, industrial and high-tech activities are likely to generate risks. Disasters always lead to the same questions: why and how did it occur? Could the damage have been avoided? What was done by those whose mission is to ensure the safety of all? The criminal justice system often appropriates these questions in order to seek answers, in a phenomenon known as judicialization or penalization. Judicialization of risky activities recently featured in the news in France when, on October 31th, 2017, the Paris Court of Appeal convicted the Grande Paroisse company and its director over the AZF disaster.

\footnotetext{
C. Lacroix (殴

Université d'Evry-Val d'Essonne - Paris-Saclay, Évry, France

e-mail: caroline.lacroix@univ-evry.fr 


\section{Judicialization and Penalization}

The term judicialization appeared in political discourse in the 1990s. It can thus be understood as the expanding role of judges in monitoring compliance by certain companies. The notion of "criminal justice" more specifically refers to "criminalization" or penalization after an accident. It is understood, first, as the recourse to criminal justice, either through the work of the public prosecutor's office or on the initiative of victims or associations. Penalization can also express "the reinforcement of penal repression", emphasizing either the propensity to question particular categories of hitherto protected citizens (local elected officials or business leaders) or to apply criminal law to activities that had been spared it in the past. The notion of penalization is then often used in a pejorative way and accompanied by a qualifier reinforcing this idea, such as that of "outrageous criminalization".

\subsection{A Global Phenomenon?}

Intervention by the criminal justice system is an integral part of the social response to a disaster. Disasters have entered the criminal field and this phenomenon is neither recent, nor uniquely French. A simple retrospective look at the legislation and practices of member countries of the European Union shows that most major transport or industrial accidents are played out on the criminal stage in all their variations and facets [10]. We mainly studied our close European neighbours: Germany, Spain, Italy, Belgium, Luxembourg and Great Britain. But beyond these few examples, we observed that other European countries do not exclude the use of criminal law in the treatment of disasters. This was the case in Switzerland following the Überlingen Air Collision that killed 71 people on July 1, 2002. A criminal trial was also held in Austria in connection with the Kaprun funicular accidental fire that caused 155 deaths on November 11, 2000. Each of these states has an administrative authority in charge of investigating the causes of the accidents. The administrative inquiry does not exclude the separate existence of a judicial inquiry and the holding of a criminal trial.

Contrary to popular belief, British disaster treatment is not limited to the issue of damage repair. The United Kingdom, often cited as a counter-example of the French criminalization movement, nevertheless tends to turn to criminal justice under the pressure of victims' lobbies. "Disaster Action", was founded as a charity in 1991 by survivors of disasters and bereaved people from the UK and overseas. They submitted to the Royal Commission on Criminal Justice a call for radical changes in the criminal justice system regarding the treatment of possible corporate crimes of violence. Thus, on April 6, 2008, the Corporate Manslaughter and Corporate Homicide Act was promulgated $[1,11,12]$. The creation of this new offence of manslaughter committed by a corporation provided a means of accountability for very serious management failings across an organisation. It is intended to work in conjunction with other forms 
of accountability such as gross negligence manslaughter for individuals and other elements of health and safety legislation.

\subsection{Why this Judicialization?}

There are several reasons for the attractiveness of criminal justice. Beyond procedural reasons, there are sociological explanations. Criminalization of disasters and referral to the criminal courts reflect both the social perception of risks and the social representation of criminal justice.

In the first place, the spirit of resignation is disappearing from our modern societies. As serious accidents multiply, disasters are no longer considered fate only, but also the result of risky human activities [2]. In one way or another, human activities may have triggered the disaster, or it may have been caused by a lack of forecasting, prevention or by inadequate safety management upstream. Meanwhile, the need for safety has become fundamental. The current trend is towards an almost absolute rejection of the inevitability of risks and the utopian affirmation of zero risk has been erected as a principle. This increased need for protection, even precaution, has found a resonance in law. Criminal law has a pronounced symbolic character. Our fellow citizens firmly believe that justice is not really done until those responsible have been given a criminal sentence.

Disasters therefore give rise to a process of dramatization of responsibilities. The criminal judge is perceived as "the only impartial interlocutor" [13], especially when the feeling of a "smothering of responsibilities" arises. Public opinion and victims share the same wish to acknowledge mistakes and identify their authors. Establishing the truth of the case is, as such, a remedy for the victim. The holding of a trial is useful not only to the victims but also to society. It constitutes a place for confrontation and dialogue, where searching for the veracity of the facts takes precedence even over the strict application of the law.

\subsection{The Protest}

This criminalization of major disasters is not unopposed. There is no shortage of arguments, both to justify the shortcomings of criminal law and to suggest other ways of managing collective accidents and/or "punishments" that are less egregious than the penal sanction. Some claim there should be sectoral criminal immunity or a reinforced presumption of innocence in highly technical fields. It is also argued that the fear of the criminal court results in a strict respecting of procedures, thus limiting innovation and ultimately undermining safety. 


\title{
2.3.1 "Just Culture" and "Blame Culture"
}

\begin{abstract}
"Just Culture" is a culture in which front-line operators and others are not punished for actions, omissions or decisions taken by them which are commensurate with their experience and training, but where gross negligence, wilful violations and destructive acts are not tolerated. [8]
\end{abstract}

Successful implementation of safety regulations results in a "just culture" reporting environment within aviation organisations, regulators and investigation authorities. This is because one element of the philosophy of "just culture" is giving the actors sufficient leeway to allow them to share their mistakes during safety investigations without the risk of being systematically prosecuted in criminal cases.

By contrast, a "blame culture" is a description given to an organisation in which people are blamed for mistakes.

In this sense, the intervention of the criminal justice system in the context of disasters would thus be an example of blame culture, unlike the philosophy of "just culture". Indeed, penalization of disasters would precisely lead to the refusal of witnesses to co-operate in investigations, invoking their right to protect themselves from criminal prosecution. This would cause a breakdown in the feedback experience. Thus, penalization would harm safety.

\subsubsection{The Case of Civil Aviation}

The protest movement against penalization is particularly prevalent in civil aviation. In 2006, the Civil Air Navigation Services Organisation (CANSO), the Royal Aeronautical Society in England (RAeS) and the French National Academy of Air and Space (ANAE), adopted a resolution on the penalization of aviation accidents in which the signatory organisations stated that they

(...) are convinced that criminal investigations and prosecutions in the wake of aviation accidents can interfere with the efficient and effective investigation of accidents and prevent the timely and accurate determination of probable cause and issuance of recommendations to prevent recurrence (...) [7].

According to these professionals, most aviation accidents result from human errors, often multiple and inadvertently committed. They declared that, in the absence of

acts of sabotage and willful or particularly egregious reckless misconduct (including misuse of alcohol or substance abuse), criminalization of aviation accidents is not an effective deterrent or in the public interest. [...] Increasing safety in the aviation industry is a greater benefit to society than seeking criminal punishment for those "guilty" of human error or tragic mistakes [7].

Such an approach found favour with the European Economic and Social Committee (EESC). In an opinion on the "Proposal for a regulation of the European Parliament and of the Council on the investigation and prevention of accidents and incidents in civil aviation", this body 
stresses the utmost importance for aviation safety of a truly independent accident investigation process free from interference from the affected parties as well as from the public, politics, media and judicial authorities. (...) EESC welcomes "Charter for just culture" agreed by the European civil aviation social partners on 31 March 2009 [4].

Thus, the European Union seems receptive to the principle of just culture. The term "just culture" is mentioned in the opening remarks of the 2010 regulation, as paragraph 24 states:

The civil aviation system should equally promote a non-punitive environment facilitating the spontaneous reporting of occurrences and thereby advancing the principle of 'just culture' [5].

As an extension of the European Charter for a Just Culture adopted by the social partners of the European civil aviation sector on 31 March 2009.

But European Union law does not promote any kind of diversion. Indeed, the assertion of the need to separate the judicial inquiry from the administrative one in the European regulations does not, in any way, compel the abandonment of the judicial inquiry or establish a hierarchy between these investigations. No primacy of the administrative inquiry is affirmed. It is at best a recommendation, without binding legal effect for the Member States.

In fact, opposing just culture and penalization is the result of a pernicious amalgam. Just culture and a criminal trial do not occur at the same time and place. Just culture seeks to continuously improve safety and not identify individual responsibilities. Although it thus promotes a non-punitive atmosphere, just culture is not a system of total impunity. Rather, it is a proactive system intended to anticipate accidents by creating a climate of confidence favourizing the identification of any type of information relevant for safety. However, just culture does not mean there cannot be prosecutions when an accident occurs, notably if it has dramatic consequences.

\section{The Expression of the Penalty}

\subsection{Foundation of Repression}

The charge of unintentional crimes is used to ensure punishment via the courts of those at the origins of catastrophes. Most disasters are caused by the offences of manslaughter or accidental injury occurring as a result of negligence, carelessness, inattention or the accidental destruction, damage deterioration of property through an explosion or fire.

These terms all refer to imprudence, negligence, breaches of regulation, whose degree of seriousness is expressed as an ordinary fault (simple negligence), characterized fault (gross negligence i.e. fault exposing others to a serious danger its author could not ignore), deliberate fault (willful misconduct i.e. breach of duty of care or prudence). 
Repression of imprudence, negligence liability, is a sensitive topic that has undergone two modifications since the entering into force of the Penal Code in 1994: first by the law of May 13th, 1996, then by the law of July 10th, 2000. These offences proceed from the following logic today: the degree of gravity of the fault constituting the offence is a function of the direct or indirect character of the causal link between this fault and the damage. When the causal link is direct, simple negligence is enough to engage the criminal responsibility of a natural person. When the causal link is indirect, the criminal responsibility of a natural person is engaged only in the case of willful misconduct or of gross negligence. To put it another way,

The criminal responsibility of a natural person requires a gravity of the fault inversely proportional to the proximity of its harmful consequences [3].

The assessment of the fault must refer to the safety due diligence relative to the circumstances and characteristics of the agent. The law of 13 May 1996 strongly urged the criminal court to take into account the situation of the perpetrator. The legislator then provides the judge with the elements on which the assessment must be based: nature of the mission or functions, powers and means of the perpetrator. These criteria invite the judge to decide on objective data. It is a question of identification, in the conduct of the missions or the functions performed, in the exercise of the attributed competences, as well as in the use of the devolved powers and means, all the elements of a normal diligence. In criminal law, error is not considered a criminal fault. Not all errors are faults. The judge is not guided by a dogmatic but by a concrete approach, and is keen to consider the system of constraints under which safety actors work.

The objective of the law of 10 July 2000 was to tighten the hypotheses of liability of natural persons, indirect perpetrators, in matters of recklessness, by means of a linkage between the causal relation and the nature of the fault. This law tends to displace the repression towards the direct authors and the legal persons who in any event, remain responsible for all forms of imprudence, however slight.

\subsection{Typology of Responsibilities}

Accidents and disasters are often caused by a combination of factors: degree of compliance with norms, rules and procedures, behaviour of safety actors. The industrial safety policy is analysed by the criminal judge, who will highlight the absence, the inefficient implementation of this policy. The judge is also interested in human and organisational factors in high-risk companies. By seeking the implication of human factors, not only can compensation be obtained but also the reparation of any damage. This power of repair of justice is most embodied in the criminal trial [9].

Today, there is a real "disasters" case law framework. The essential respect for safety in high-risk organisations is recalled through the judgments rendered. Analysis of the various court decisions makes it possible to draw up both a typology of the behaviours that can lead to convictions and the profile of potentially responsible 
persons in case of a disaster. The chain of causalities extends from mere agents to decision makers. Court decisions include the whole decision-making and safety hierarchies of the company. These malfunctions in terms of safety can also be attributed to the legal person. In the end, these court decisions also make it possible to build HOF approaches to industrial safety in a large group.

\subsubsection{Natural Person}

In the search for multiple responsibilities, there is a real methodology implemented by magistrates that is reflected in the form of the decisions rendered, which present an originality in the way they are written. The most obvious manifestation of this modus operandi appears in the ranking of potential authors, through a process of “ grouping by responsibility".

A first group consists of the company managers and executives. These are the persons for whom the works are carried out and who have an economic interest in the activity at the origin of the harmful event. Imprudence or negligence committed at the highest hierarchical level of the company is therefore sanctioned. Then there is a second group, those who could be called the "men of art", the entrepreneurs and architects. They are potentially responsible since they are the ones who build and create. Another group of officials is sometimes made up of what might be called "safety officers". Ultimately there is the person directly responsible for the disaster, the one that we could call "the lamplighter". This first link in the causal chain is often an artisan or a worker. However, the faults committed by these immediate perpetrators are often only evidence of much more serious mistakes committed upstream, some of which can be blamed on public actors.

\subsubsection{Legal Person}

Disasters often have structural causes and the lack of safety at the origin of the drama is sometimes the result of an explicit corporate policy. Through the implementation of the liability of legal persons, the judge can adequately sanction the organisational factors of a company. These safety dysfunctions can be attributed to the legal person since the entering into force of the Penal Code in 1994, a major innovation.

The liability of a legal person may coexist with that of natural persons. It can be engaged for a simple fault of recklessness whatever the nature of the causal link. The decriminalization resulting from the reform of 10 July 2000 seeking to distinguish between direct and indirect causality, has been established only for the benefit of natural persons. Thus, the purpose is to compensate the decriminalization of natural persons by the responsibility of legal persons. 


\section{The Judge and Expert Opinions}

As stated earlier in this chapter, in France, an industrial disaster usually leads to two different investigations, pursuing different objectives: an administrative inquiry and a judicial inquiry. The administrative inquiry aims to quickly determine the technical causes of the accident, to remedy them. The purpose of the judicial inquiry is to establish the responsibilities and can therefore be a lengthier process. Let us recall that the primary purpose of the criminal trial is not to identify a culprit, but to respond to an incrimination (for manslaughter and accidental injury) which is not specific to collective accidents. This investigation is also carried out in order to explain the reasons of this accident to the victims and their relatives. And lastly, such an investigation allows access to the judge, which is a fundamental right.

Disasters tend to be complex phenomena. Faced with multiple potential causes, which could be either technical and/or human, the judge is obliged to call on expert opinion to clarify the reality. The expert report ordered by the judge must be at the service of the truth, and must enlighten the court, allow it to understand what has happened so that it can judicially establish the potential liabilities. The truth is not absolute and is fixed in the current state of science.

The administrative and the judicial inquiries complement each other. Both provide elements of research that help advance safety. The administrative report is useful to the judge. Thus, for the plane crash that occurred on March 24, 2001 in SaintBarthélemy, the correctional court of Basse-Terre took into account the opinion issued by the experts of the BEA ${ }^{1}$ to render its judgment of November 15, 2006.

The issues addressed in disasters cases are mostly scientific, giving a prominent place to expertise in contemporary criminal trials. These cases do not present any particular legal technicality, but show difficulties related to the technical fields covered. However, the judge is often unfamiliar with these questions. Unlike investigators and experts, they do not have any specific technical competence. Naturally, they can undertake training in order to acquire better knowledge of the field, to understand the various documents, to be able to ask the right questions, to be in a position not to be manipulated by one party or the other [6].

The expert is appointed by the judge to provide them with elements within their field of technical competence established in the sole interest of the manifestation of the truth. In all cases, the expert's performance must be of high quality and impartial. The expert does not have to rule on the merits of the case. They deliver scientific knowledge to the magistrate, but do not take part in the decision making, which falls exclusively within the jurisdiction of the judge. It is up to the judge to decide, not the expert. The conclusions of the experts are binding neither on the judges nor on the parties. The criminal judge will include in their decision the elements of the report which allow them to form a conviction. In the trial of the Mont Blanc tunnel, three experts had been appointed to determine the causes of the fire. Two of them drew on three private expert reports, one of which was paid for by the insurer of the truck.

\footnotetext{
${ }^{1}$ The French Bureau of Enquiry and Analysis for Civil Aviation Safety (Bureau d'enquêtes et d'analyses).
} 
The theses proposed by the experts were rigorously analysed, weighed and compared with the other factual elements. The investigating judge then also sought the advice of a professor from the University of Lausanne; this last thesis was chosen because it presented no contradiction with the facts, the chronology of the events having been verified by simulation.

Disasters shed a different light on the relationship between magistrates and experts. Expertise, which should be an enlightening tool, can prove to be a delaying tool. It is necessary to be aware of the difficulties related to the limited number of specialized experts, in fields such as aviation. This may raise the issue of the independence of the experts, who might sometimes be linked in one way or another to someone who is potential responsible party for the event.

\section{Conclusion}

Ending the criminalization of disasters could be an excessive approach and negative for safety and security, specifically in high-risk industries. It is through criminal law that society warns its members and stresses the essential values to be protected. The judicial decision has an undeniable pedagogical function. It serves as a benchmark in the interest of risk prevention, with regards to safety actors in general, beyond the protagonists of the disaster. This approach is part of an objective to prevent the repetition of disasters and encourages a better consideration of human and organisational factors.

\section{References}

1. C. Clarkson, Corporate culpability. Web J. Curr. Leg. Issues 2 (1998)

2. M.-A. Descamps, Catastrophe et responsabilité. Revue française de sociologie 13(3), 376-391 (1972). https://doi.org/10.2307/3320531

3. F. Desportes, F. Le Gunehec, Droit pénal général, vols. 798-4. Economica (2002)

4. EESC, TEN/416 (European Economic and Social Committee, Brussels, 2010)

5. European Parliament, Regulation (EU) No 996/2010 of the European Parliament and of the Council. Off. J. Eur. Union (L 295/35) (2010), https://www.easa.europa.eu/document-library/ regulations/regulation-eu-no-9962010

6. K. Favro, M. Lobe-Lobas, J.-P. Markus, in L'expert dans tous ses états. A la recherche d'une déontologie de l'expert, ed. by K. Favro, M. Lobe-Lobas, J.-P. Markus. Dalloz (2016)

7. Joint resolution regarding criminalization of aviation accidents (2006), www.flightsafety.org

8. Just culture (n.d.), Eurocontrol, https://www.eurocontrol.int/articles/just-culture

9. C. Lacroix, La réparation des dommages en cas de catastrophes. LGDJ (2008)

10. C. Lacroix, M.-F. Steinlé-Feuerbach, La judiciarisation des grandes catastrophes - Approche comparée du recours à la justice pour la gestion des grandes catastrophes (de type accidents aériens ou ferroviaires), ed. by C. Lacroix, M.-F. Steinlé-Feuerbach. Dalloz (2015) 
11. R. Matthews, Blackstone's Guide to the Corporate Manslaughter and Corporate Homicide Act 2007 (Blackstone Press, 2008)

12. Ministry of Justice, A guide to the Corporate Manslaughter and Corporate Homicide Act 2007. UK Ministry of Justice. Crown copyright (2007)

13. D. Salas, L'éthique politique à l'épreuve du droit pénal. Revue des Sciences Criminelles $\mathbf{1 6 3}$ (2000)

Open Access This chapter is licensed under the terms of the Creative Commons Attribution 4.0 International License (http://creativecommons.org/licenses/by/4.0/), which permits use, sharing, adaptation, distribution and reproduction in any medium or format, as long as you give appropriate credit to the original author(s) and the source, provide a link to the Creative Commons license and indicate if changes were made.

The images or other third party material in this chapter are included in the chapter's Creative Commons license, unless indicated otherwise in a credit line to the material. If material is not included in the chapter's Creative Commons license and your intended use is not permitted by statutory regulation or exceeds the permitted use, you will need to obtain permission directly from the copyright holder. 